\title{
HMG-CoA reductase inhibitors induce apoptosis of lymphoma cells by promoting ROS generation and regulating Akt, Erk and p38 signals via suppression of mevalonate pathway
}

\author{
X-F Qi ${ }^{*}{ }^{1,5}$, L Zheng ${ }^{2,5}$, K-J Lee ${ }^{3}$, D-H Kim ${ }^{3}$, C-S Kim ${ }^{4}$, D-Q Cai ${ }^{1}$, Z Wu ${ }^{1}$, J-W Qin ${ }^{1}$, Y-H Yu ${ }^{1}$ and S-K Kim ${ }^{\star, 4}$
}

Statins, the inhibitors of 3-hydroxy-3-methylglutaryl coenzyme A (HMG-COA) reductase, are widely used cholesterol-lowering drugs. Convincing evidence indicates that statins stimulate apoptotic cell death in several types of proliferating tumor cells in a cholesterol-lowering-independent manner. The objective here was to elucidate the molecular mechanism by which statins induce lymphoma cells death. Statins (atorvastatin, fluvastatin and simvastatin) treatment enhanced the DNA fragmentation and the activation of proapoptotic members such as caspase-3, PARP and Bax, but suppressed the activation of anti-apoptotic molecule Bcl-2 in lymphoma cells including A20 and EL4 cells, which was accompanied by inhibition of cell survival. Both increase in levels of reactive oxygen species (ROS) and activation of p38 MAPK and decrease in mitochondrial membrane potential and activation of Akt and Erk pathways were observed in statin-treated lymphoma cells. Statin-induced cytotoxic effects, DNA fragmentation and changes of activation of caspase-3, Akt, Erk and p38 were blocked by antioxidant ( $N$ acetylcysteine) and metabolic products of the HMG-CoA reductase reaction, such as mevalonate, farnesyl pyrophosphate (FPP) and geranylgeranyl pyrophosphate (GGPP). These results suggests that HMG-CoA reductase inhibitors induce lymphoma cells apoptosis by increasing intracellular ROS generation and p38 activation and suppressing activation of Akt and Erk pathways, through inhibition of metabolic products of the HMG-CoA reductase reaction including mevalonate, FPP and GGPP.

Cell Death and Disease (2013) 4, e518; doi:10.1038/cddis.2013.44; published online 28 February 2013

Subject Category: Cancer

It is known that malignant lymphoma $(\mathrm{ML})$, a heterogeneous disease with highly variable clinical course and prognosis, is the most prevalent type of adult leukemia. ${ }^{1-3}$ Most patients with MLs in clinical course are aggressive and soon after diagnosis require intensive treatment. ${ }^{4,5}$ Both the defective balance between pro- and anti-apoptotic molecules, and aberrant upregulation of prosurvival mechanism have been shown to be related to resistance of $M L$ cells to radiation therapy and chemotherapy. ${ }^{6,7}$ Previous clinical studies have demonstrated that symptomatic ML can be effectively treated with purine analogs, glucocorticoids, alkylating agents or monoclonal antibodies. However, some patients with relapsed or refractory disease have limited therapeutic options. Therefore, there is an urgent need to discover less toxic and more effective drugs for ML patients.
Inhibitors of 3-hydroxy-3-methyl glutaryl coenzyme A (HMG-CoA) reductase (statins) are used to treat hypercholesterolemia. Convincing evidence from both in vitro and in vivo data has demonstrated that statins exert pleiotropic actions beyond their lipid-lowering effects, including immune regulation $^{8}$ and cancer prevention. ${ }^{9,10}$ Statins have been demonstrated to induce cell cycle arrest and cell death in various cancer cells such as multiple myeloma cells, ${ }^{11}$ pancreatic cancer cells, ${ }^{12}$ non-small lung cancer cells, ${ }^{13}$ waldenstrom macroglobulinemia cells, ${ }^{14}$ glioblastoma cell lines $^{15}$ and HT29 cells. ${ }^{16}$ A recent study has shown that simvastatin inhibits proliferation of MCF-7 cells in parallel with an increase in reactive oxygen species (ROS) production. ${ }^{17}$ Another lipophilic statin, atorvastatin, has also been shown to elevate levels of myocardial protein oxidation and lipid

\footnotetext{
${ }^{1}$ Key Laboratory for Regenerative Medicine of Ministry of Education, and Department of Developmental and Regenerative Biology, Ji Nan University School of Life Science and Technology, Guangzhou, People's Republic of China; ${ }^{2}$ School of Environmental Science and Engineering, Guangdong University of Technology, Guangzhou, People's Republic of China; ${ }^{3}$ Department of Environmental Medical Biology, Yonsei University Wonju College of Medicine, Wonju, Gangwon, Republic of Korea and ${ }^{4}$ Department of Microbiology, Yonsei University Wonju College of Medicine, Wonju, Gangwon, Republic of Korea

*Corresponding author: X-F Qi, Key Laboratory for Regenerative Medicine of the Ministry of Education, Department of Developmental and Regenerative Biology, Ji Nan University School of Life Science and Technology, Guangzhou, People's Republic of China. Tel: + 8620 85222687; Fax: + 8620 85222711; E-mail: qixufeng@jnu.edu.cn.

or S-K Kim, Department of Microbiology, Yonsei University Wonju College of Medicine, Wonju, Republic of Korea. Tel: +82337410323 ; Fax: +86 33 748 2709; E-mail: kim6@yonsei.ac.kr

${ }^{5}$ These authors contributed equally to this work and should be considered first authors.

Keywords: statins; lymphoma cells; apoptosis; mevalonate pathway

Abbreviations: ROS, reactive oxygen species; $\triangle \Psi \mathrm{m}$, mitochondrial membrane potential; HMG-CoA, 3-hydroxy-3-methylglutaryl coenzyme A; Mev, mevalonate; FPP, farnesyl pyrophosphate; GGPP, geranylgeranyl pyrophosphate; DCFH-DA, $2^{\prime}, 7^{\prime}$-dichlorodihydrofluorescin diacetate; HO, Hoechst 33342; PI, propidium iodide; DAPI, 4,6-diamidino-2-phenylindole; NAC, N-acetylcysteine; JC-1, 5,5',6,6'-tetrachloro-1,1',3,3'-tetraethylbenzimidazolylcarbocyanine iodide; SOD, superoxide dismutase; CAT, catalase

Received 04.12.12; revised 21.1.13; accepted 28.1.13; Edited by G Ciliberto
} 
peroxidation. ${ }^{18}$ Moreover, a high-dose of atorvastatin induces oxidative DNA damage in human peripheral blood lymphocytes. ${ }^{19}$

Previous studies have demonstrated that cancer cells produce higher levels of ROS than normal cells and this contributes to cancer progression. ${ }^{20,21}$ To maintain ROS at tolerable physiological levels, cancer cells possess an antioxidant defense system that includes glutathione and glutathione-dependent enzymes such as superoxide dismutase and catalase to eliminate ROS. ${ }^{22,23}$ Increased ROS generation selectively sensitizes oncogenically transformed and cancer cells, but not non-transformed cells, to cell death, ${ }^{22}$ indicating that neoplastic cells are more vulnerable to increased intracellular oxidative stress. ${ }^{24}$ Given these previous findings, we hypothesized that statins exert at least some of their cytotoxic effects by increasing oxidative stress depending on cell type.

In the present study, we investigated the effects of statins including atorvastatin, fluvastatin and simvastatin on survival of lymphoma cells such as A20 and El4 cells, and explored the potential underlying mechanism. We demonstrated that statin induces lymphoma cells apoptosis by increasing intracellular ROS generation and p38 activation and suppressing activation of Akt and Erk pathways, through inhibition of metabolic products of the HMG-CoA reductase reaction including mevalonate, farnesyl pyrophosphate (FPP) and geranylgeranyl pyrophosphate (GGPP).

\section{Results}

Fluvatatin-induced cytotoxicity in Iymphoma cells. The effects of statins on viability of peripheral blood mononuclear cells (PBMCs) and lymphoma cell lines (A20 and EL4 cells) were determined using the EZ-CyTox Cell Viability Assay Kit as described in method section. Cells were incubated with atorvastatin, fluvastatin or simvastatin at concentrations ranging from $0-5 \mu \mathrm{m}$ for 24 and/or $48 \mathrm{~h}$, respectively. Our results revealed that, statins at low concentration of 1.25 and $2.5 \mu \mathrm{m}$ exerted minimal effects on the ability of primarily isolated PBMCs after treatment for $24 \mathrm{~h}$, even they significantly inhibited the cell viability at $5 \mu \mathrm{m}$. However, each statin significantly decreased the viabilities of A20 and EL4 cells after treatment of $24 \mathrm{~h}$, even at lowest concentration of $1.25 \mu \mathrm{m}$. Furthermore, statins inhibited viability of lymphoma cells in a dose- and time-dependent manner. However, fluvastatin showed higher cytotoxicity towards lymphoma cells than atorvastatin or simvastatin. Even at $24 \mathrm{~h}$, fulvatatin $(5 \mu \mathrm{M})$ inhibited the viability of A20 cells and EL4 cells by $\sim 50 \%$ and $40 \%$, respectively (Figure 1a). Therefore, fluvastatin was selected to use throughout the following experiments.

After treatment with fluvastatin $(0-20 \mu \mathrm{m})$ for $24 \mathrm{~h}$, cell death was then examined by using trypan blue staining. As shown in Figure $1 b$, fluvastatin markedly induced cell death of A20 cells and EL4 cells in a dose-dependent manner. Even at $2.5 \mu \mathrm{m}$, fluvastatin induced $\sim 25 \%$ of cell death of two cancer cells.

Apoptosis was involved in fluvastatin-induced cytotoxicity towards lymphoma cells. To explore apoptosis whether involved in fluvastatin-induced cell death in lymphoma cells, we next investigated the amount of subG1 DNA in cancer cells that treated with fluvastatin using flow cytometry. As shown in Figure 2, the treatment of lymphoma cells with fluvastatin resulted in the increased accumulation of cells in the sub-G1 phase in a dose-dependent manner. To further elucidate apoptosis stage of cancer cells induced by fluvastatin, Hoechst 33342 (HO)/propidium iodide (PI) double staining method was used. The plasma membrane of viable cells is only slightly permeable to $\mathrm{HO}$, leading to light-blue nuclear fluorescence. However, $\mathrm{HO}$ efficiently crosses the plasma membrane of apoptotic cells due to increased membrane permeability, causing bright-blue fluorescence of the nuclei. On the other hand, PI only penetrates cells with damaged membranes, leading to bright-red fluorescence of nuclei. Thus, intact light-blue nuclei ( $\mathrm{HO}+/ \mathrm{PI}-)$, condensed/ fragmented bright-blue nuclei ( $\mathrm{HP}++/ \mathrm{PI}-)$, condensed/ fragmented pink nuclei $(\mathrm{HO}++/ \mathrm{PI}++)$, intact pink nuclei $(\mathrm{HO}+/ \mathrm{PI}++)$ were considered to indicate viable, early apoptotic, late apoptotic (secondary necrotic) and necrotic cells, respectively. Following treatment with fluvastatin at concentrations of 5 and $10 \mu \mathrm{m}$ for $24 \mathrm{~h}, \mathrm{HO} / \mathrm{PI}$ double staining showed mainly necrotic cell death of primary PBMCs. However, massive apoptotic, but not necrotic, cell death was observed in both A20 and EL4 cells (Figures 3a-b). To explore the dose-response effects of fluvastatin on apoptosis, both cancer cells were incubated with fluvastatin at concentrations ranging from $0-20 \mu \mathrm{M}$ for $24 \mathrm{~h}$. Annexin V-FITC/PI staining showed that fluvastatin induced apoptosis in cancer cells in a dose-dependent manner (Figures $3 c$ and d). Taken together, these findings suggest that apoptosis is involved in fluvastatin-induced cytotoxicity in lymphoma cells.

Fluvastatin-induced nuclear condensation. Apoptotic morphological changes were assessed by staining with 4,6diamidino-2-phenylindole (DAPI) and fluorescence microscopy. After treatment with fluvastatin at concentrations of 5 and $10 \mu \mathrm{M}$ for $24 \mathrm{~h}$, marked morphological changes induced by fluvastatin in a dose-dependent manner were observed, such as nuclear condensation, nuclear fragmentation, and apoptotic bodies (Figures $4 a$ and b). Transmission electron microscopy was utilized to further assess the features of the apoptotic cell death induced by fluvastatin. The control cells exhibited normal cell morphology, but features of apoptotic cells such as chromatin condensation and apoptotic bodies were observed after treatment with fluvastatin at concentrations of 5 and $10 \mu \mathrm{m}$ for $24 \mathrm{~h}$ (Figure $4 \mathrm{c}$ ). To explore the effect of fluvastatin on cell apoptosis, apoptosis was also detected by DNA fragmentation assay. DNA fragmentation was significantly increased after treatment with fluvastatin in a dose-dependent manner (Figure 4d). Taken together, these data indicated that nuclear condensation and DNA fragmentation were involved in fluvastatin-induced apoptotic death of A20 and EL4 cells.

Fluvastatin treatment led to decreased mitochondrial membrane potential $(\Delta \Psi \mathrm{m})$. To further document the involvement of mitochondrial dysfunction in lymphoma cell apoptosis induced by fluvastatin, we next measured $\Delta \Psi \mathrm{m}$ in A20 cells with flow cytometry analysis and JC-1 staining. Cells were incubated with fluvastatin at concentrations 

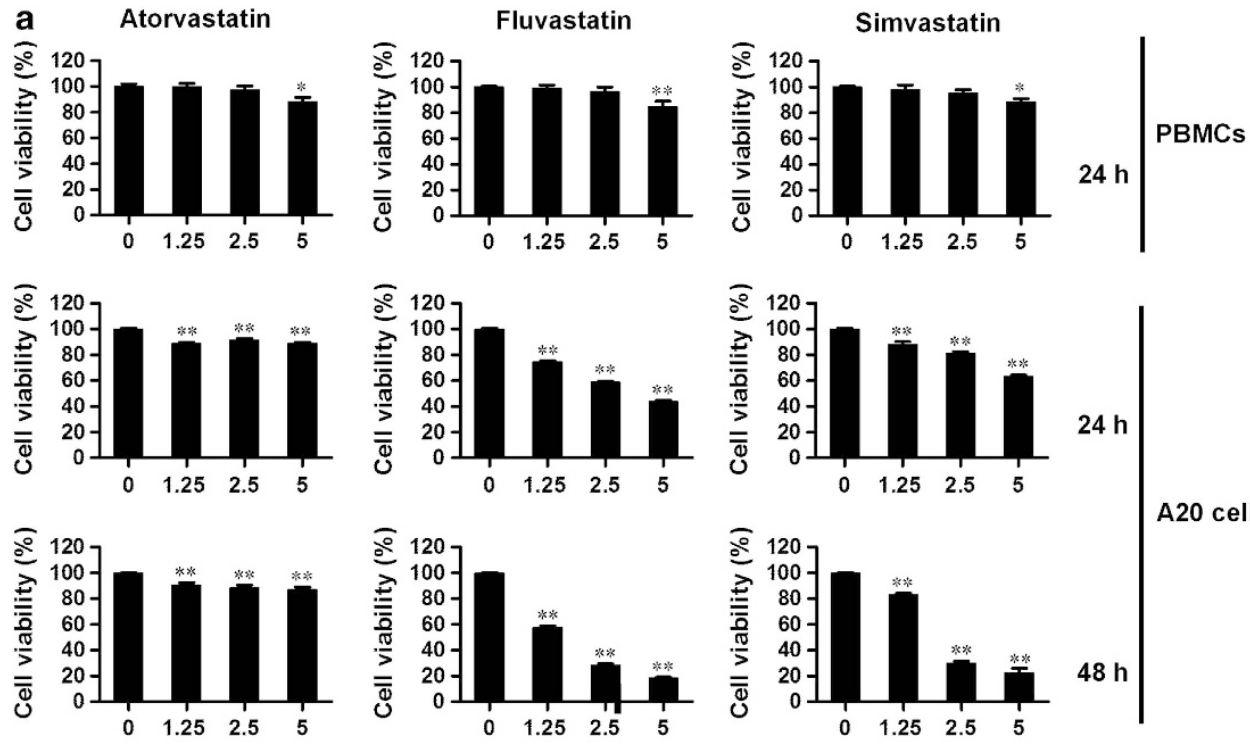

A20 cells
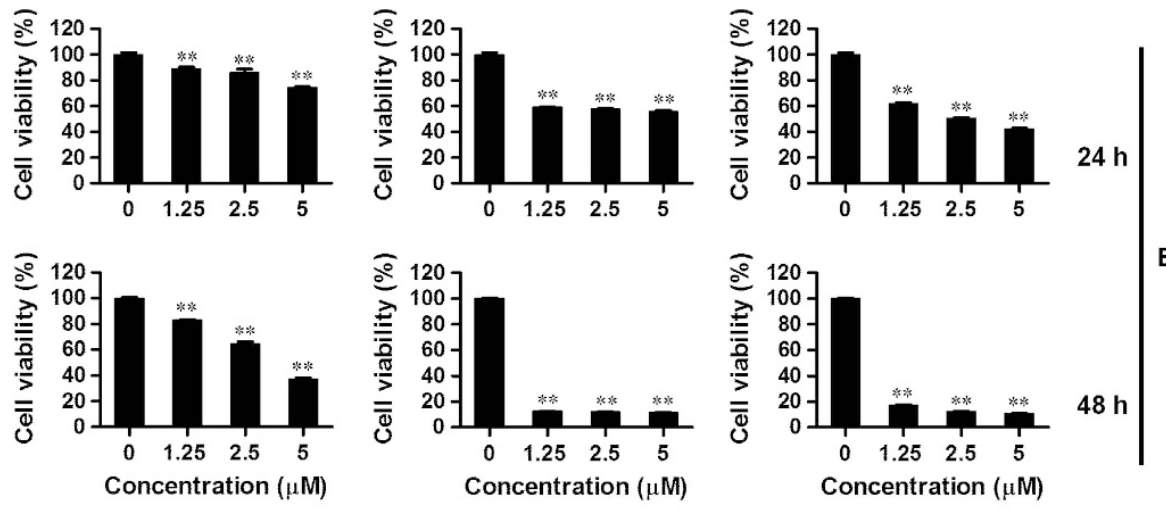

EL4 cells
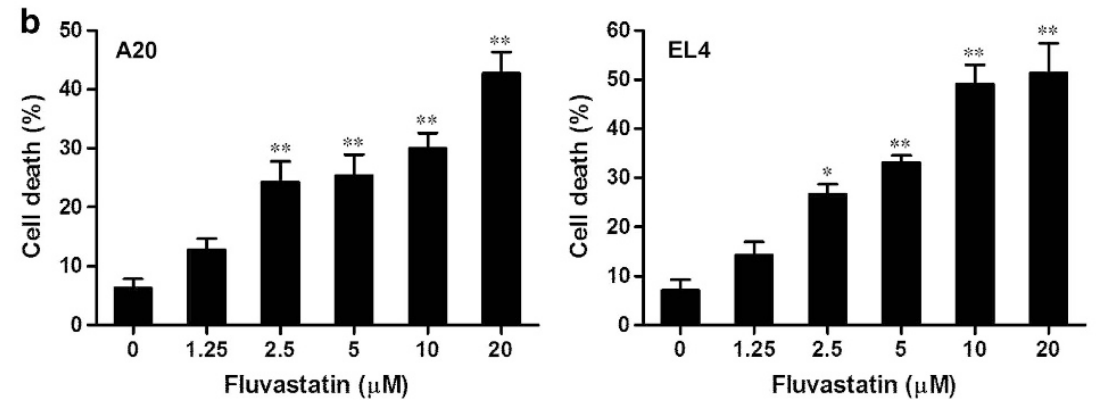

Figure 1 Cytotoxic effects induced by statins. (a) PBMCs and lymphoma cells were incubated with statins $(0-5 \mu \mathrm{m})$ for $24 \mathrm{~h}$ or $48 \mathrm{~h}$. Cell viability was quantified using EZCyTox Cell Viability Assay Kit and expressed as the percentage of the viability of resting cells. Results are presented as mean \pm S.E.M. of three separate experiments conducted in duplicate, ${ }^{*} P<0.05,{ }^{*} P<0.01$ versus resting cells. (b) Lymphoma cells were incubated with fluvastatin $(0-20 \mu \mathrm{g} / \mathrm{ml})$ for $24 \mathrm{~h}$. Cell death was then quantified by trypan blue staining as described above. Results are presented as mean \pm S.E.M. of three separate experiments conducted in duplicate, ${ }^{*} P<0.05$, ${ }^{* \star} P<0.01$ versus resting cells

ranging from $0-20 \mu \mathrm{m}$ for $12 \mathrm{~h}$ and analyzed by using flow cytometry. As shown in Figures $5 \mathrm{a}$ and $\mathrm{b}$, with increase in the concentration of fluvastatin, the number of cells emitting green fluorescence (apoptosis) increased from $18.24 \%$ in control cells to $54.42 \%$ in those treated with fluvastatin at $20 \mu \mathrm{m}$. Statistical analysis from three independent data showed that treatment with fluvastatin significantly reduced $\Delta \Psi \mathrm{m}$ in a dose-dependent manner, as indicated by a decrease in $\mathrm{red} / \mathrm{green}$ ratio, from $0.3082 \pm 0.0031$ in the control to $0.0592 \pm 0.0022$ in fluvastatin-treated cells (Figure 5c).

Effects of fluvastatin on apoptosis-related molecules. To further explore the molecular mechanism contributing to statins-induced apoptosis, the expression of apoptosisrelated proteins was examined by western blot analysis. As shown in Figure 6a, the expression of cleaved caspase-3 was remarkably enhanced in both A20 and EL4 cells 

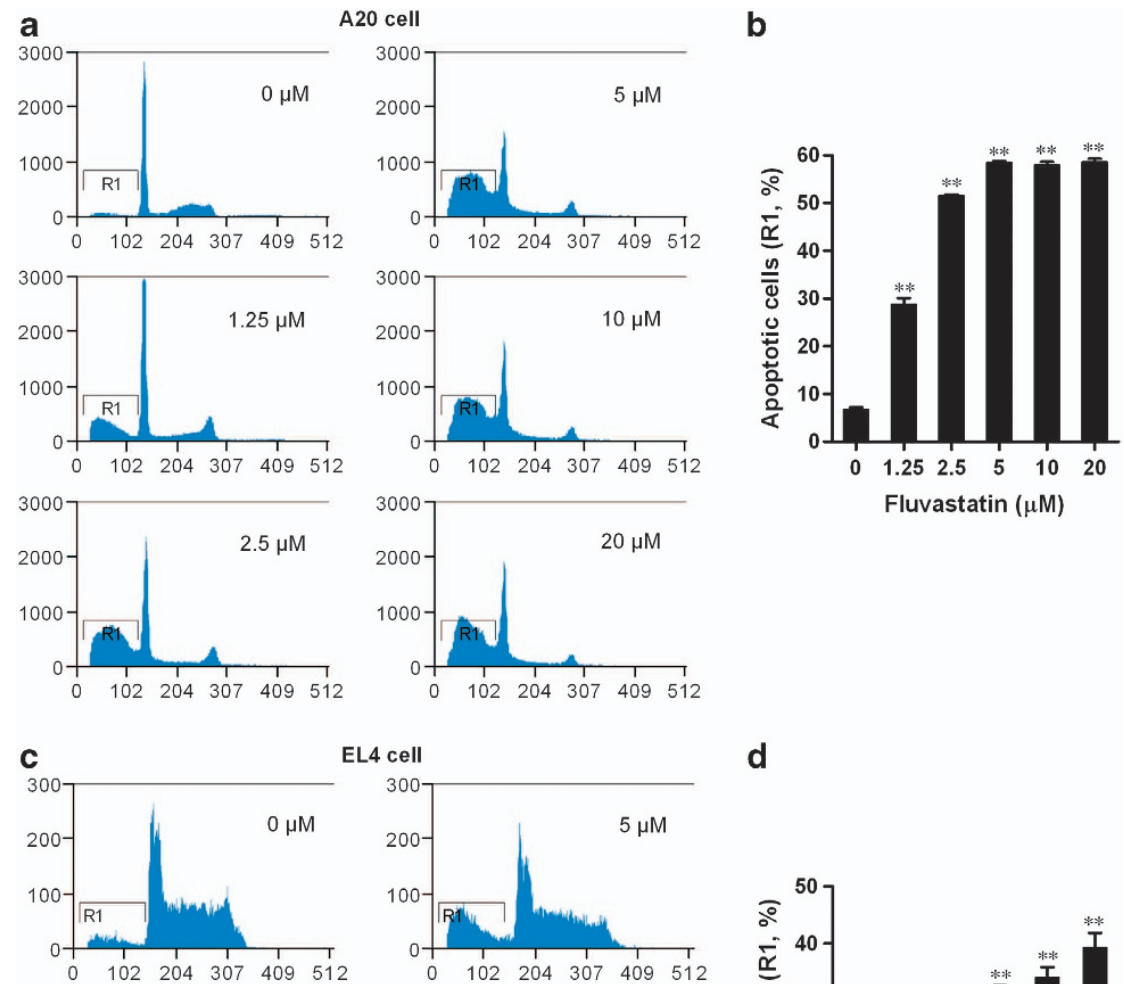

EL4 cell

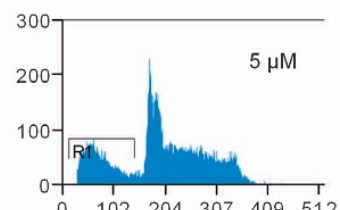

d
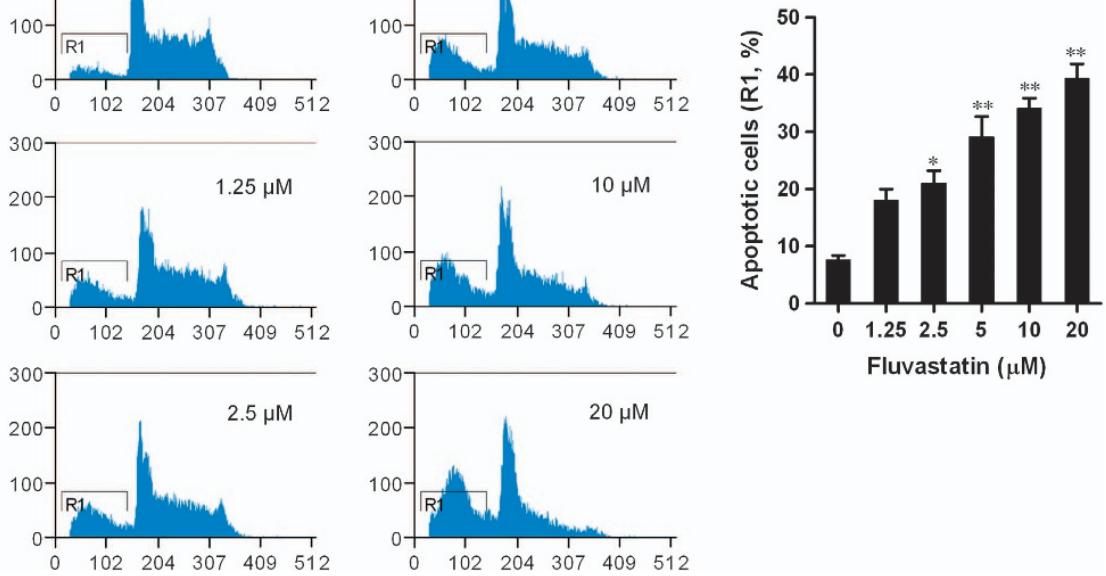

Figure 2 Effects of fluvastatin on DNA content of lymphoma cells. A20 cells ( $\mathbf{a}$ and $\mathbf{b})$ and EL4 cells (c and $\mathbf{d})$ were incubated with fluvastatin (0-20 $\mu \mathrm{m})$ for $24 \mathrm{~h}$. DNA contents in sub-G1 phase were analyzed by using flow cytometry as described in above. Representative flow cytometry images were shown (a and $\mathbf{c})$. (b and $\mathbf{d})$ The percentage of apoptotic cells in sub-G1 phase was evaluated by statistic analysis, and the results are presented as mean \pm S.E.M. of three separate experiments, ${ }^{\star} P<0.05$, ${ }^{* *} P<0.01$ versus resting cells

following treatment with atorvastatin, fluvastatin or simvastatin at $5 \mu \mathrm{m}$ for $12 \mathrm{~h}$, respectively. In addition, fluvastatin $(5 \mu \mathrm{M})$ greatly increased the expression of cleaved caspase-3 in both two cancer cells in a time-dependent manner (Figure 6b). We also treated A20 cells with fluvastatin at concentrations ranging from $0-10 \mu \mathrm{m}$ for $12 \mathrm{~h}$. The expressions of cleaved caspase- 3 and cleaved PARP, the wellknown characteristics of apoptosis, were significantly increased in a dose-dependent manner (Figure 6c). The apoptosis defects are mainly determined by a defective balance among pro- and anti-apoptotic members of the $\mathrm{Bcl}-2$ family, often related to resistance of cancer cells to chemotherapy $^{6}$. The expression of Bax, a pro-apoptotic protein, was increased while expression of $\mathrm{Bcl} 2$, an antiapoptotic protein, was decreased in fluvastatin-treated A20 cells (Figure 6c). Moreover, the activity of caspase-3 in A20 cells was also observed to increase in a dose-dependent manner after treatment with fluvastatin (Figure 6d).

Furthermore, Akt pathway is the major anti-apoptotic molecular that confer the survival advantage and resistance of cancer cells against various chemotherapeutic agents. ${ }^{25}$ We first investigated whether fluvastatin $(5 \mu \mathrm{m})$ downregulated constitutive Akt activation in lymphoma cells. As shown in Figure 6e, constitutive phosphorylation (activation) of Akt was suppressed by fluvastatin in a time-dependent manner. We also analyzed the activation of MAPK cascades including p38 and Erk in A20 cells. We found that fluvastatin markedly increased phosphorylation of p38 MAPK and decreased the phosphorylation of Erk pathway in a time-dependent manner, respectively (Figure $6 \mathrm{e}$ ). These results indicate that 
a

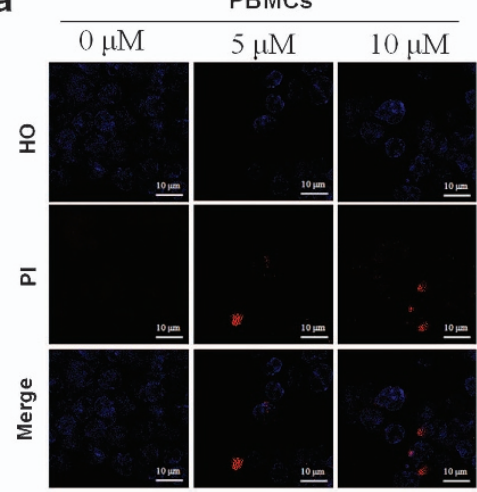

A20

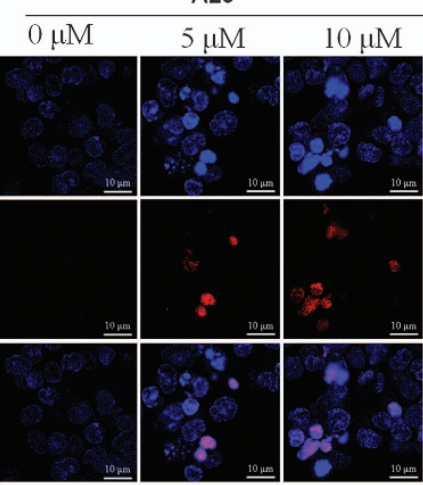

EL4

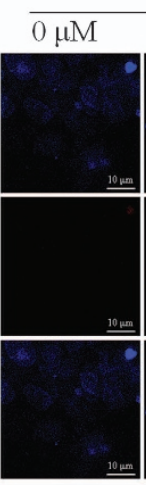

b

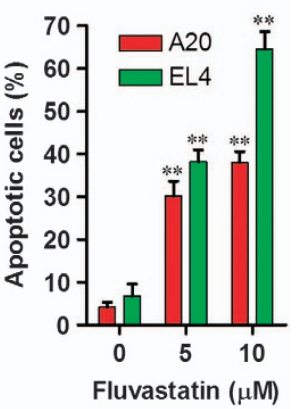

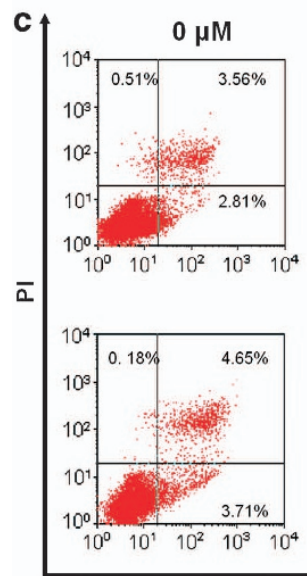
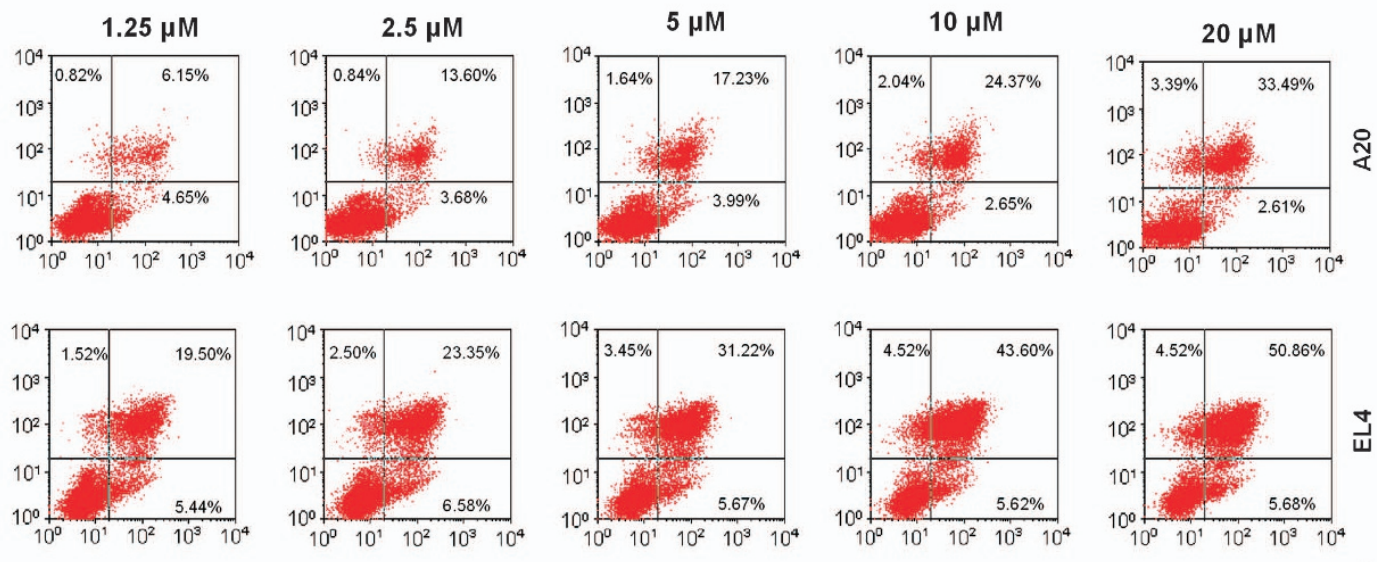

Annexin V-FITC
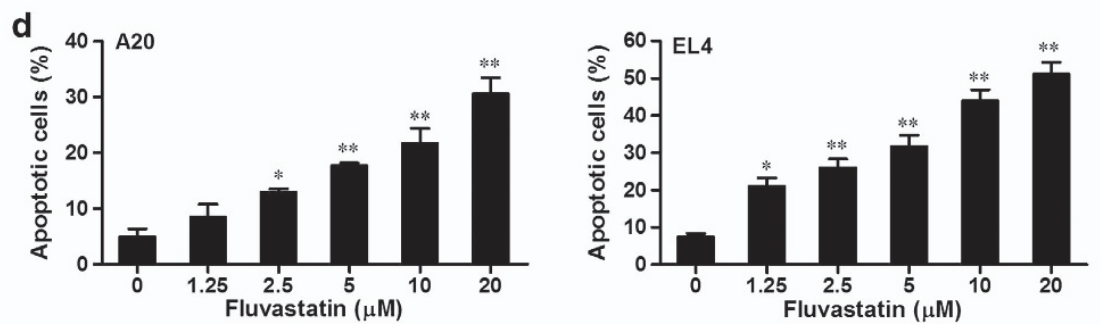

Figure 3 Apoptosis induced by fluvastatin in lymphoma cells. (a) PBMCs and lymphoma cells were incubated with fluvastatin $(0-10 \mu \mathrm{m})$ for $24 \mathrm{~h}$. The model of cell death was examined by using $\mathrm{HO} / \mathrm{PI}$ double staining and confocal microscopy, typical images of HO/PI-stained cells were then captured. Percentage of apoptosis in lymphoma cells was statistically analyzed as described in the Method section (b). Results are presented as mean \pm S.E.M. of three separate experiments, ${ }^{* *} P<0.01$ versus resting cells. (c and d) Lymphoma cells were incubated with fluvastatin $(0-20 \mu \mathrm{m})$ for $24 \mathrm{~h}$. The apoptosis was then examined with annexin V-FITC/PI staining and flow cytometry analysis. (c) The representative images of flow cytrometry analysis were shown. Cell population with FITC/PI', FITC ${ }^{+} / \mathrm{PI}^{-}$, $\mathrm{FITC}^{+} / \mathrm{PI}^{+}$, $\mathrm{FITC}^{-} / \mathrm{PI}^{+}$were regarded as living, early apoptotic, late apoptotic and necrotic cells, respectively. (d) The percentage of apoptotic A20 and EL4 cells were statistically analyzed as described above. Results are presented as mean \pm S.E.M. of three separate experiments, ${ }^{*} P<0.05,{ }^{*} P<0.01$ versus resting cells

fluvastatin can suppress the activation of Akt and Erk pathways, but promote the activation of p38 MAPK pathway in lymphoma cells.

Oxidative stress was involved in fluvastatin-induced cytotoxicity. To investigate the involvement of oxidative stress in fluvastatin cytotoxicity, we examined the important oxidative stress marker, intracellular ROS levels, in lymphoma cells following treatment with fluvastatin at concentrations ranging from $0-20 \mu \mathrm{m}$ for $6 \mathrm{~h}$. As shown in Figure 7, treatment of lymphoma cells with fluvastatin significantly increased intracellular ROS generation in a dose-dependent manner, suggesting the potential involvement of oxidative stress in the cytotoxic action of fluvastatin. To further explore the signaling mechanism of ROS in fluvastatin-induced cytotoxicity towards lymphoma cells, we incubated A20 cells with fluvastatin $(5 \mu \mathrm{M})$ in the presence or absence of the thiol antioxidant $\mathrm{N}$-acetylcysteine (NAC). Cells were treated with $5 \mathrm{mM}$ NAC for $2 \mathrm{~h}$ before and during $12 \mathrm{~h}$ exposure to fluvastatin, cell viability, western blotting and DNA fragmentation were then analyzed. As shown in Figure 8a, NAC could significantly block increase in the expression of cleaved caspase 3 and p38 MAPK regulated by fluvastatin, whereas the fluvastatin-inhibited activation of Akt and Erk pathway 

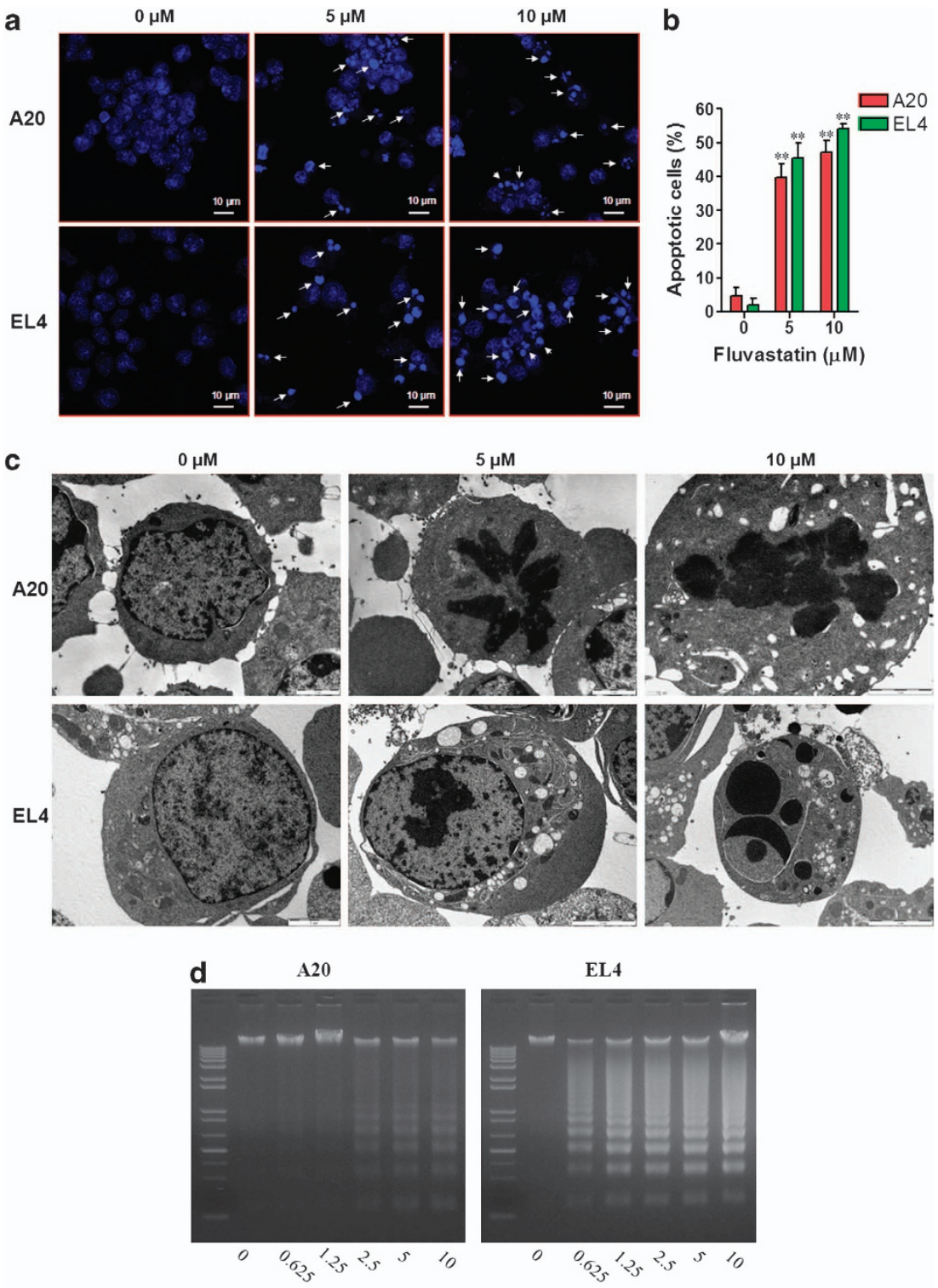

EL4

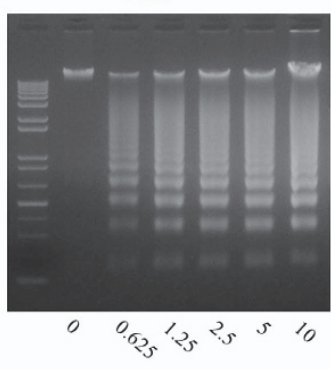

Fluvastatin $(\mu \mathrm{M})$

Figure 4 Fluvastatin induced nuclear condensation and DNA fragmentation in lymphoma cells. Lymphoma cells were incubated with fluvastatin (0-10 $\mu \mathrm{M})$ for $24 \mathrm{~h}$. (a and b) Apoptotic morphological changes such as nuclear condensation and nuclear fragmentation were assessed by staining with DAPI and fluorescence microscopy. Representative images were shown (a). Percentatge of apoptotic cells was evaluated as described in the Marerials and Methods section (b). (c) Chromatin condensation and the formation of apoptotic bodies were evaluated by Transmission electron microscopy. (d) DNA fragmentation was assessed by using DNA fragmentation assay

were markedly blocked by NAC. In addition, both cell viability inhibition and DNA fragmentation induced by fluvastatin were remarkably suppressed by NAC (Figures $8 \mathrm{~b}$ and $\mathrm{c}$ ).

\section{Mevalonate pathway contributes to fluvastatin-induced apoptosis in lymphoma cells. To examine the signaling mechanism for fluvastatin-induced cytotoxicity towards A20 cells, we incubated cells with fluvastatin in the presence or absence of mevalonate (Mev, $200 \mu \mathrm{m}$ ), GGPP ammonium salt (GGPP, $10 \mu \mathrm{M}$ ) or FPP ammonium salt (FPP, $10 \mu \mathrm{M}$ ). Western blotting data in Figure $8 \mathrm{a}$ showed that the increase in expression of cleaved caspase 3 and p38 MAPK regulated by fluvastatin were markedly suppressed, whereas the}

fluvastatin-inhibited activation of Akt and Erk pathway were markedly blocked by Mev, FPP or GGPP. In addition, both cell viability inhibition and DNA fragmentation induced by fluvastatin were remarkably suppressed by Mev, FPP or GGPP (Figures $8 \mathrm{~b}$ and $\mathrm{c}$ ). Taken together, these data indicate that mevalonate pathway may contribute to fluvastatin-induced apoptosis in lymphoma cells.

\section{Discussion}

Convincing evidence from both in vitro and mouse model data suggest that statins can be used as a potential cancer therapeutic depending on the type of cancer cell, but the 

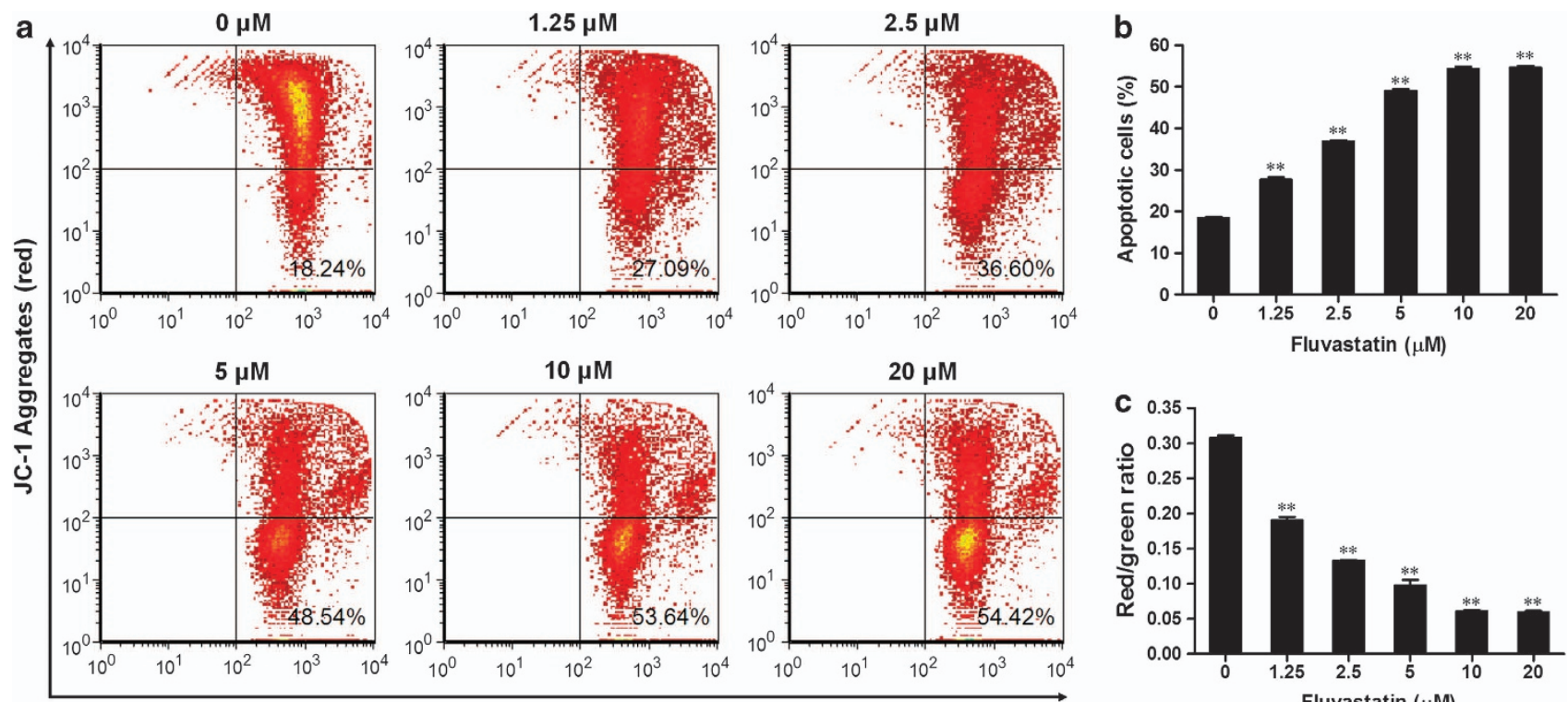

JC-1 Monomer (green)

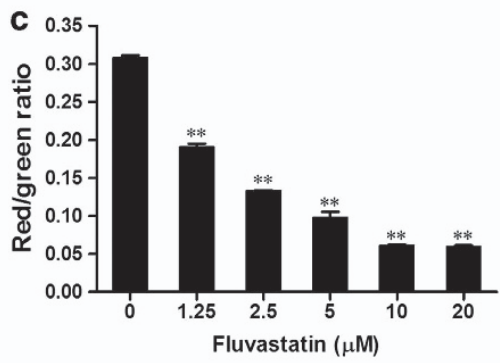

Figure 5 Fluvastatin treatment led to decrease in mitochondrial membrane potential. Cells were incubated with fluvastatin at concentrations ranging from $0-20 \mu \mathrm{m}$ for $12 \mathrm{~h}$. The changes in mitochondrial membrane potential were examined by using JC-1 staining and flow cytometry analysis. (a) Representative images of flow cytometry analysis showing changes in mitochondrial membrane potential. The green emission was analyzed in fluorescent channel 1 (FL 1, JC-1 green fluorescence) and the red emission in channel 2 (FL 2, JC-1 red fluorescence). (b) Graphical representation of the apoptotic cells (R4 quadrant). (c) Graphical representation of the ratio of red to green examined by using JC-1 staining and flow cytometry analysis. Results are presented as mean \pm S.E.M. of three separate experiments, ${ }^{* *} P<0.01$ versus resting cells

effects of statins on ML cells and related mechanism have been veiled. To clarify this issue, we examined whether different statins (atorvastatin, fluvastatin and simvastain) induce cytotoxicity in A20 cells and EL4 cells. Our results revealed that statins markedly suppressed the viability of lymphoma cells in a dose- and time-dependent manner. However, fluvastatin showed more cytotoxicity towards lymphoma cells than other two statins, by increasing intracellular ROS generation and p38 activation and suppressing activation of Akt and Erk pathways, through inhibition of metabolic products of the HMG-CoA reductase reaction including mevalonateFPP and GGPP.

Previous studies have reported that statins can induce cell death in various cancer cells in a cell type-dependent manner. ${ }^{11,13,15,17,26}$ These previous data are consistent with our results showing that statins, especially fluvastatin, induced significant inhibition of the viability of lymphoma cells. We next documented that apoptosis was responsible for fluvastatin-induced cytotoxicity towards A20 cells using flow cytometry, $\mathrm{HO} / \mathrm{PI}$ double staining, TEM, DNA fragmentation and annexin V-FITC staining, indicating that fluvastatin treatment directly induced an apoptotic death in lymphoma cells.

The increasing knowledge about the processes that regulate apoptosis has identified several targets, which can be used as specific cell death markers, including the changes in mitochondrial membrane potential. ${ }^{27}$ The decrease in mitochondrial membrane potential and the release of cytochrome $\mathrm{C}$ into the cytoplasm may occur upon apoptotic stimulation. Caspase-9 is activated due to the combination of released cytochrome $\mathrm{C}$ and apoptotic protease activating factor- 1 , thereby processing other caspase members, including caspase- 3 and caspase-7, to initiate a caspase cascade, which leads to apoptosis. ${ }^{28,29}$ Despite we did not directly examined the release of cytochrome $\mathrm{C}$, our results revealed a dose-dependent decrease in the mitochondrial membrane potential and increase in the activation of caspase3 in A20 cells following treatment with fluvastatin, suggesting that the mitochondrial pathway is also involved in fluvastatininduced cell apoptosis. Because PARP is one of the main cleavage targets of caspase- $3,{ }^{30}$ we next examined the cleavage of PARP. As expected, the cleavage of PARP was observed in lymphoma cells, suggesting that cells were undergoing apoptosis. ${ }^{31}$ On the other hand, the apoptosis defects are mainly determined by a defective balance among pro- and anti-apoptotic members of the $\mathrm{Bcl}-2$ family, often related to resistance of CLL B-cells to chemotherapy. ${ }^{32}$ In this study, the expression of Bax was increased but that of Bcl2 was decreased in fluvastatin-treated lymphoma cells, indicating that the resistance of lymphoma cells to apoptosis can be blocked by the addition of fluvastatin.

Several signaling pathways, including Akt, Erk and p38 were showed to be important for cell cycle progression and proliferation. ${ }^{33-35}$ In the present study, treatment with fluvastatin markedly suppressed the activation of Akt and Erk. However, the phosphorylation of p38 pathway was markedly increased by fluvastatin in A20 cells (Figure 6e), indicating the involvement of these three pathways in fluvasatin-induced apoptotic death in lymphoma cells. The hypothesis was further supported by previous studies. For instance, statin can suppress the activation of Akt, a major prosurvival pathway, in cancer cells. ${ }^{36}$ Furthermore, p38 pathway-mediated apoptosis was also observed in different cell types. ${ }^{37,38}$ In addition, Erk activation is essential for 

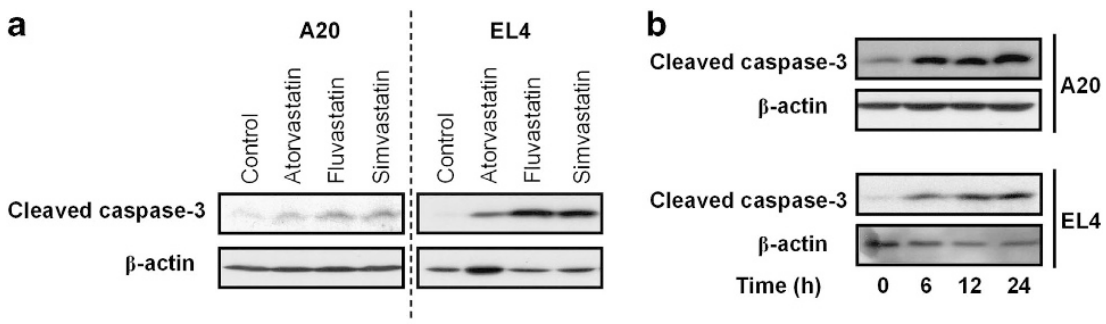

C

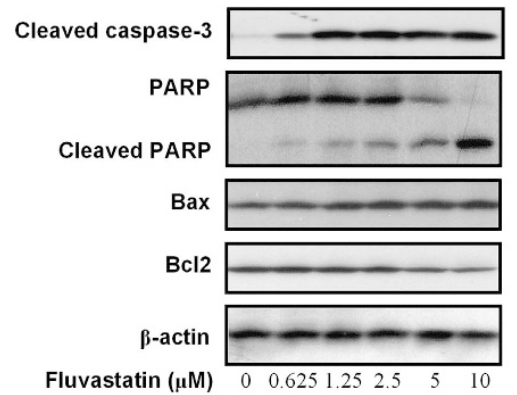

d

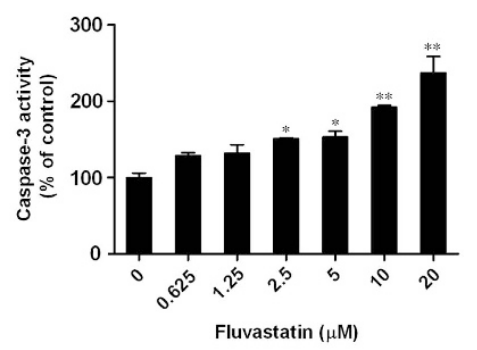

e

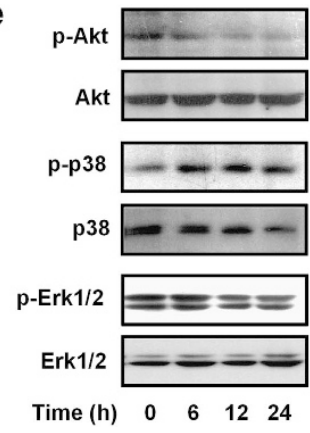

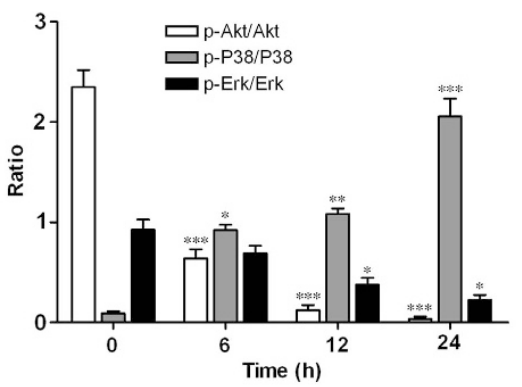

Figure 6 Effects of fluvastatin on apoptosis- and survival-related molecules. (a) Lymphoma cells were incubated with fluvastatin $(5 \mu \mathrm{m})$ for $12 \mathrm{~h}$. The expression of cleaved caspase-3 was examined by western blotting. (b) Lymphoma cells were incubated with fluvastatin ( $5 \mu \mathrm{m})$ for indicated times $(0-24 \mathrm{~h})$, and the expression of cleaved caspase-3 was then examined. (c) A20 cells were incubated with fluvastatin (0-10 $\mu \mathrm{m})$ for $12 \mathrm{~h}$, and the expression of cleaved caspase-3, PARP, Bax and Bcl-2 was examined. (d) A20 cells were incubated with fluvastatin $(0-20 \mu \mathrm{m})$ for $12 \mathrm{~h}$, and the activity of caspase- 3 was then evaluated by using caspase-3 activity kit. Results are presented as mean \pm S.E.M. of three separate experiments, ${ }^{*} P<0.05,{ }^{* *} P<0.01$ versus resting cells. (e) A20 cells were incubated with fluvastatin $(5 \mu \mathrm{M})$ for $12 \mathrm{~h}$, and the expression of Akt, p38 and Erk was examined by western blotting. Left panel was the representative image. The activation levels of these three kinases were evaluated by the phosphorylation ratio of Akt, p38 and Erk (right panel). Data are presented as mean \pm S.E.M. of three separate experiments, ${ }^{\star} P<0.05,{ }^{\star \star} P<0.01,{ }^{\star \star *} P<0.001$ versus resting cells

carcinogenesis, ${ }^{39}$ and constitutively activated Erk is found in a variety of human cancers. ${ }^{40}$

Recent studies indicate that increased intracellular ROS generation may be involved in statin-induced cytotoxicity in MCF-7 breast cancer cells. ${ }^{17}$ Furthermore, atorvastatin treatment is associated with elevated levels of myocardial protein oxidation and lipid peroxidation in a mouse model. ${ }^{18}$ These previous studies are at least partly consistent with our data showing the potential involvement of intracellular ROS generation in fluvastatin-induced cytotoxicity towards lymphoma cells. Inhibition of HMG-CoA reductase by statins is limiting for the biosynthesis of not only cholesterol, but also other important isoprenoid intermediary metabolites such as dolichols, and the electron transport chain proteins heme A and ubiquinone. A lack of these non-steroid isoprenoids, which are related to antioxidant status, might cause oxidative stress. ${ }^{41,42}$ Moreover, neoplastic cells are more vulnerable to increase in ROS level because they function with a heightened basal level of ROS-mediated signaling. ${ }^{20,43}$
Combining these previous studies with our observations in this study, we hypothesize that statins, especially fluvastatin, cause a breakdown of the antioxidant defense system and thereby increasing the accumulation of intracellular ROS to levels that exceed the cell's metabolic capabilities to maintain an acceptable physiological range. In support of this idea, a well-known antioxidant, NAC, suppressed the DNA fragmentation and cytotoxicity induced by fluvastatin (Figure 8). Other studies have also suggested that statins can induce cytotoxicity in an oxidative stress-dependent manner. For example, atorvastatin has been demonstrated to induce oxidative DNA damage in human peripheral blood lymphocytes. ${ }^{19}$ Furthermore, increased intracellular ROS production is responsible for lovastatin-induced cell death of k-ras-transformed thyroid cells. ${ }^{44}$ Although they use a different experimental system, these studies partially support our results showing that fluvastatin-induced cytotoxicity is accompanied by an increase in intracellular ROS generation in A20 cells. These results further indicate that increased accumulation of 

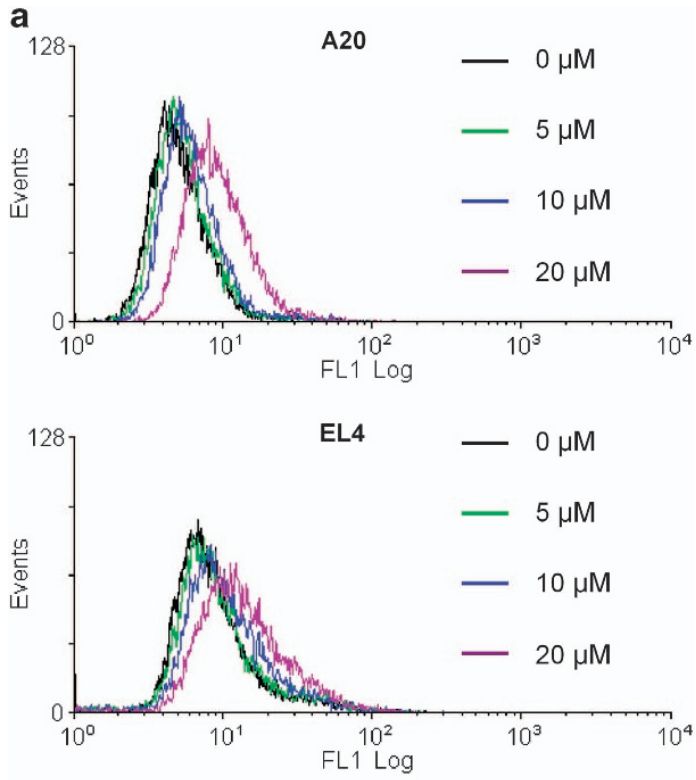

b

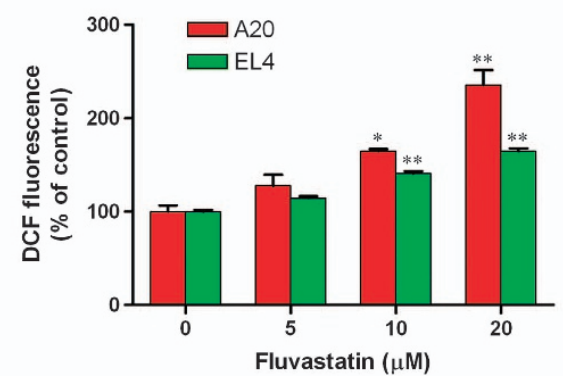

Figure 7 Fluvastatin promoted the generation of ROS in lymphoma cells. Lymphoma cells were incubated with fluvastatin $(0-20 \mu \mathrm{m})$ for $6 \mathrm{~h}$. (a) Representative images of ROS generation were captured by oxidation of $2^{\prime}, 7^{\prime}$-dichlorodihydrofluorescin diacetate and flow cytometry analysis. (b) Intracellular ROS generation was examined by using DTX-880 multimode microplate reader. Data are presented as mean \pm S.E.M. of three separate experiments, ${ }^{\star} P<0.05,{ }^{*} P<0.01$ versus resting cells

intracellular superoxide is involved in the death of lymphoma cells induced by fluvastatin.

Statins are known to lower cholesterol by inhibiting HMGCoA reductase, thereby blocking the mevalonate pathway. Besides reducing cholesterol biosynthesis, inhibition of mevalonate by statins also leads to a reduction in the synthesis of isoprenoids such as FPP and GGPP. ${ }^{45}$ However, these intermediates are involved in the positive modulation of several non-steroid isoprenoids (for example, heme $A$, coenzyme Q10 and dolichols) that are related to antioxidant status, and a reduction in these non-steroid isoprenoids induces oxidative stress. ${ }^{41,46}$ Coenzyme Q10 (CoQ10), an important intracellular antioxidant, has membrane stabilizing effects and has an important role in cellular respiration and defending proteins from oxidation. ${ }^{47}$ In addition, dolichol is a polyprenol compound that is synthesized by the general isoprenoid pathway from acetate via mevalonate and FPP and is broadly distributed in membranes. Dolichol functions as a free-radical scavenger in the cell membranes, ${ }^{48}$ and may interact with Vitamin $\mathrm{E}$ and polyunsaturated fatty acids to form a highly matched free-radical-transfer chain whose malfunctioning might be involved in statin toxicity. ${ }^{49}$ In view of these previous studies, it is hypothesized that treatment with statin increases intracellular oxidative stress by disrupting the antioxidant defense system in certain transformed and cancer cells, particularly by inhibiting biosynthesis of isoprenoid antioxidants such as CoQ10 and dolichol. This idea is further supported by our results showing that fluvastatin-induced cytotoxicity, apoptotic signaling and DNA fragmentation were significantly decreased by addition of Mev, FPP, GGPP (Figure 8).

In conclusion, the present study demonstrates that treatment with HMG-CoA reductase inhibitors induced apoptotic death in ML cells, by increasing intracellular ROS generation and p38 activation and suppressing activation of Akt and Erk pathways, through inhibition of metabolic products of the HMG-CoA reductase reaction including mevalonate, FPP and GGPP. Moreover, decrease in mitochondrial membrane potential was also contributed in HMG-CoA reductase inhibitor-induced apoptosis. This new understanding supports the development of mevalonate pathway-targeted therapy with HMG-CoA reductase inhibitors as direct therapeutic agents for treating $\mathrm{ML}$.

\section{Materials and Methods}

Reagents. Atorvastatin (calcium salt, $\left.\left(\mathrm{C}_{33} \mathrm{H}_{34} \mathrm{FN}_{2} \mathrm{O}_{5}\right)_{2} \mathrm{Ca} 3 \mathrm{H}_{2} \mathrm{O}\right)$ was obtained from Pfizer (Groton, CT, USA). Fluvastatin (sodium salt, $\mathrm{C}_{24} \mathrm{H}_{25} \mathrm{FNNaO}_{4}$ ) and simvastatin (sodium salt, $\mathrm{C}_{25} \mathrm{H}_{39} \mathrm{O}_{6} \mathrm{Na}$ ) were purchased from Calbiochem (La Jolla, CA, USA). DCFH-DA, HO, PI, DAPI, NAC, Mev, GGPP ammonium salt and FPP ammonium salt were purchased from Sigma-Aldrich Co (St. Louis, MO, USA). 5,5',6,6'-tetrachloro-1,1',3,3'-tetraethylbenzimidazolylcarbocyanine iodide (JC-1) was purchased from Molecular Probes Inc. (Eugene, OR, USA). Antibodies against cleaved caspase-3, poly ADP-ribose polymerase (PARP), cleaved PARP, Bax, Bcl2, Akt, phospho-Akt (Ser473), p38 MAPK, phospho-p38 MAPK, Erk1/2, phosphor-Erk1/2, $\beta$-actin and HRP-conjugated goat anti-rabbit IgG were from Cell Signaling Technology (Beverly, MA, USA). A sensitive western blotting luminal reagent was obtained from Santa Cruz Biotechnology Inc. (Santa Cruz, CA, USA).

Cell culture. A20 and EL4 lymphoma cells (Korean Cell Line Bank, Seoul, Korea) were cultured in RPMI 1640 medium (BioWhittaker Inc., Walkersville, MD, USA) containing $10 \%$ fetal bovine serum, $100 \mathrm{U} / \mathrm{ml}$ penicillin and $100 \mu \mathrm{g} / \mathrm{ml}$ streptomycin (all from BioWhittaker Inc., Walkersville, MD, USA) at $37^{\circ} \mathrm{C}$ in a $5 \%$ $\mathrm{CO}_{2}$ incubator. In experiments described below, the medium was exchanged for RPMI 1640 medium containing 2\% fetal bovine serum. PBMCs, isolated from C57BL/6 mice, were incubated as described above and used as a normal control.

Cell viability assay. Cell viability was analyzed using EZ-CyTox Cell Viability Assay Kit (Daeil Lab Service Co Ltd, Seoul, Korea) according to the manufacturer's instructions. In brief, dispense $90 \mu \mathrm{L}$ of cell suspension $\left(1 \times 10^{4}\right.$ cells) in a 96-well plate. After $4 \mathrm{~h}, 10 \mu \mathrm{l}$ of various concentrations of statins or pharmacological reagents dissolved in medium or medium alone was added into corresponding wells. The plate was incubated for indicated time, $10 \mu \mathrm{l}$ of EZCyTox Cell Viability Assay Kit solution was then added to each well of the plate followed by $2 \mathrm{~h}$-incubation at $37^{\circ} \mathrm{C}$ in a $5 \% \mathrm{CO}_{2}$ incubator, and the absorbance at $450 \mathrm{~nm}$ was detected with a DTX-880 multimode microplate reader (Beckman Coulter Inc., Fullerton, CA, USA.) The percentage of cell viability was then calculated by the following formula: cell viability $(\%)=$ (mean absorbency in test wells)/(mean absorbency in control wells) $\times 100$.

In addition, cell death was also analyzed with hemocytometer through trypan blue staining. The percentage of cell death was calculated by the following formula: cell death $(\%)=($ number of cells stained by trypan blue)/(total number of cells) $\times 100$.

DNA flow cytometric analysis. After treatment with fluvastatin, cells were harvested, washed twice with ice-cold phosphate-buffered saline (PBS), fixed with $75 \%$ ethanol at $-20^{\circ} \mathrm{C}$ overnight, washed again and then incubated with RNase 
A $\left(25 \mu \mathrm{g} / \mathrm{ml}\right.$, Bio Basic Inc., Markham, Ontario, Canada) at $37^{\circ} \mathrm{C}$ for $30 \mathrm{~min}$. Cells were washed once with PBS and incubated with PI $(50 \mu \mathrm{g} / \mathrm{ml})$ for $30 \mathrm{~min}$ at room temperature in the dark. The cells were resuspended in $500 \mu \mathrm{l}$ PBS and subjected to flow cytometry on a Cytomics FC500 flow cytometer, followed by data analyses using Summit version 5.2 software (Beckman Coulter). The cells with sub-G0/G1 peak were evaluated as DNA degradation caused by apoptosis.

a
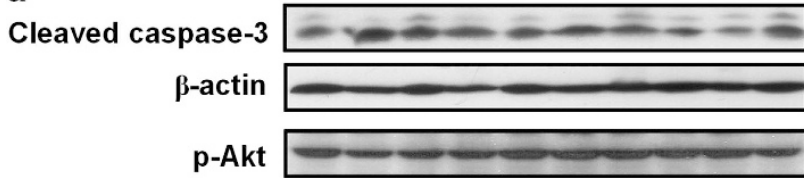

Akt

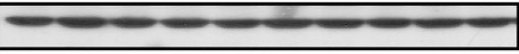

p-p38

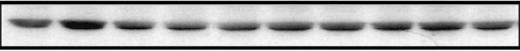

p38

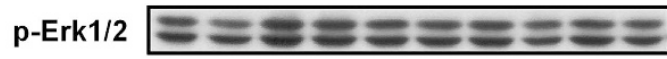

Erk1/2

\begin{tabular}{l|c|c|c|c|c|c|c|c|c|c}
\hline Fluva & - & + & + & + & + & + & - & - & - & - \\
\hline Mev & - & - & + & - & - & - & + & - & - & - \\
\hline FPP & - & - & - & + & - & - & - & + & - & - \\
\hline GGPP & - & - & - & - & + & - & - & - & + & - \\
\hline NAC & - & - & - & - & - & + & - & - & - & + \\
\hline
\end{tabular}
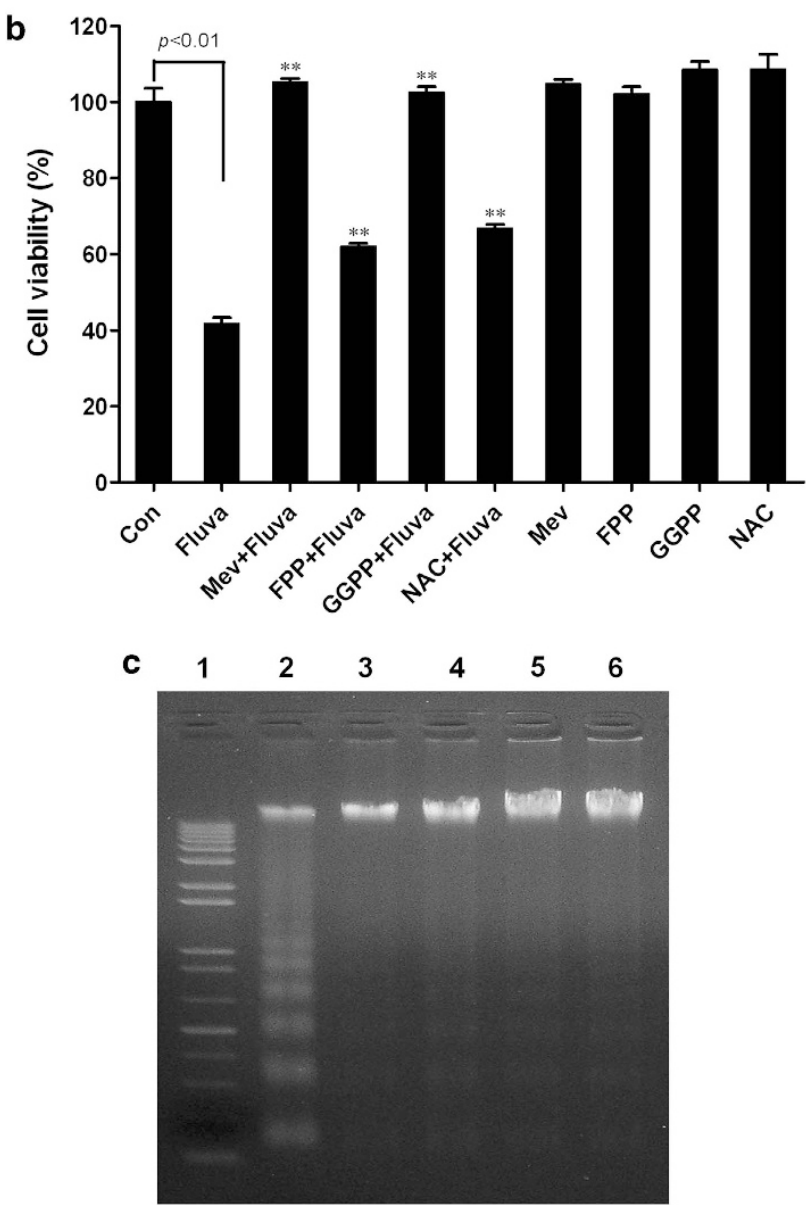

HO/PI double staining. Cells were incubated with either $1 \mu \mathrm{g} / \mathrm{ml} \mathrm{HO}$ or $5 \mu \mathrm{g} / \mathrm{ml} \mathrm{Pl}$ at $37^{\circ} \mathrm{C}, 5 \% \mathrm{CO}_{2}$ for $15 \mathrm{~min}$ in the dark and collected by centrifugation. The cell pellets were fixed in $4 \%$ formaldehyde, washed with ice-cold PBS, resuspended, and a fraction of the suspension was smeared on a slide. The slide was air dried, mounted with VECTASHIELD mounting medium and examined under a DMI 4000 fluorescence microscope (Leica, Wetzlar, Germany). Morphological assessment of apoptosis and necrosis was performed as follows: intact light-blue nuclei $(\mathrm{HO}+/ \mathrm{PI}-)$, condensed/fragmented bright-blue nuclei $(\mathrm{HP}++/ \mathrm{PI}-)$, condensed/fragmented pink nuclei $(\mathrm{HO}++/ \mathrm{PI}++)$, intact pink nuclei $(\mathrm{HO}+/ \mathrm{PI}++)$ were considered to indicate viable, early apoptotic, late apoptotic (secondary necrotic) and necrotic cells, respectively. A total of 500 cells from four randomly selected fields were counted, and the number of apoptotic cells was expressed as a percentage of the total number of cells scored.

DNA fragmentation assay. After treatment, cells were harvested in a $1.5 \mathrm{ml}$ Eppendorf tube, washed with PBS and resuspended in $400 \mu$ lysis buffer (10 mm Tris pH 8.0, $10 \mathrm{~mm} \mathrm{NaCl}, 10 \mathrm{~mm}$ EDTA, $1 \%$ SDS and $100 \mu \mathrm{g} / \mathrm{ml}$ Proteinase $\mathrm{K}$ ) and incubated at $65^{\circ} \mathrm{C}$ overnight. Seventy-five microlitres of potassium acetate (8 M) was then added and the samples were incubated at $4{ }^{\circ} \mathrm{C}$ for $15 \mathrm{~min}$. Seven hundred and fifty microlitres of chloroform was added into the Eppendorf tube, which was then mixed vigorously and centrifuged $(12000 \times g)$ at room temperature for $10 \mathrm{~min}$. The supernatant was transferred into a new Eppendorf tube and $750 \mu \mathrm{l}$ ethanol was added, followed by overnight incubation of the sample at $-20^{\circ} \mathrm{C}$. DNA was acquired by centrifugation $(12000 \times \mathrm{g}, 10 \mathrm{~min})$ of the sample, washed, dried, and dissolved in $50 \mu \mathrm{l}$ TE buffer $(10 \mathrm{~mm}$ Tris- $\mathrm{HCl}, 1 \mathrm{~mm}$ EDTA, pH 8.0). Five micrograms of DNA were analyzed on $2.0 \%$ agarose gel.

Annexin V and PI staining. Phosphatidylserine on the cell surface was detected with Annexin V-FITC Apoptosis Detection Kit I (BD Pharmingen, San Diego, CA, USA) according to the manufacturer's instructions. In brief, cells were washed twice with cold PBS and resuspended in $100 \mu$ l annexin-V binding buffer, followed by incubation with FITC-conjugated annexin V and PI for $15 \mathrm{~min}$ at room temperature in the dark. The cells were resuspended in $500 \mu \mathrm{l}$ binding buffer and analyzed by Cytomics FC500 flow cytometer (Beckman Coulter, Fullerton, CA, USA). Data were analyzed using Summit version 5.2 software (Beckman Coulter, Fullerton, CA, USA).

Detection of changes in mitochondrial membrane potential by JC-1. Mitochondrial membrane potential was evaluated by using JC-1 (Molecular Probes) staining and flow cytometry analysis. The JC-1 powder was dissolved in dimethyl sulfoxide to make a stock solution at concentration of $5 \mathrm{mg} /$ $\mathrm{ml}$. Lymphoma cells were incubated with $\mathrm{JC}-1(1 \mu \mathrm{g} / \mathrm{ml}$, diluted with fresh media) at $37^{\circ} \mathrm{C}$ for $15 \mathrm{~min}$ in the dark, washed and resuspended in $500 \mu \mathrm{l}$ PBS. Cells were then subjected to flow cytometry on a Cytomics FC500 flow cytometer (Beckman Coulter). Data analyses were performed using Summit version 5.2 software (Beckman Coulter). The cationic dye JC-1 accumulates and aggregates in intact mitochondria, emitting a bright red fluorescence. With disruption of the mitochondrial membrane potential, mitochondrial aggregates do not form, but rather the dye remains in monomeric form in the cytoplasm, emitting green fluorescence. Therefore, the values of mitochondrial membrane potential from each sample were expressed as ratios of red fluorescence intensity over green fluorescence intensity.

Figure 8 Fluvastatin-induced cytotoxicity was reversed by mevalonate, FPP, GGPP, and NAC. (a) A20 cells were incubated with fluvastatin $(5 \mu \mathrm{m})$ in the presence or absence of mevalonate $(200 \mu \mathrm{M})$, FPP $(10 \mu \mathrm{m})$, GGPP $(10 \mu \mathrm{m})$ and NAC ( $5 \mathrm{~mm}$ ) for $12 \mathrm{~h}$, and the expression of cleaved caspase-3 and phosphorylation of Akt, p38 and Erk were examined by western blotting. (b and c) A20 cells were incubated with fluvastatin $(5 \mu \mathrm{M})$ in the presence or absence of mevalonate $(200 \mu \mathrm{M}), \operatorname{FPP}(10 \mu \mathrm{M}), \mathrm{GGPP}(10 \mu \mathrm{m})$ and NAC $(5 \mathrm{~mm})$ for $24 \mathrm{~h}$. (b) The cell viability was quantified by using EZ-CyTox Cell Viability Assay Kit and expressed as the percentage of the viability of resting cells. Results are presented as mean \pm S.E.M. of three separate experiments conducted in duplicate, ${ }^{* *} P<0.01$ versus cells treated with fluvastatin. (c) The DNA fragmentation was examined by using DNA fragmentation assay. Lane 1, Marker; Lane 2, fluvastatin; Lane 3, fluvastatin + mevalonate; Lane 4, fluvastatin + FPP; Lane 5, fluvastatin + GGPP; Lane 6, fluvastatin + NAC 
Western blotting analysis. Cells were washed twice with ice-cold PBS and resuspended in $150 \mu \mathrm{l}$ RIPA cell lysis buffer (Sigma-Aldrich Co, St. Louis, MO, USA), mixed completely, incubated on ice for $30 \mathrm{~min}$, and followed by centrifugation $12000 \times g$ for $20 \mathrm{~min}$ at $4{ }^{\circ} \mathrm{C}$. Supernatants were then stored at $-80^{\circ} \mathrm{C}$ until use. Protein concentrations were determined using the Bio-Rad Protein Assay (Bio-Rad Laboratories, Hercules, CA, USA). Equal proteins ( $30 \mu \mathrm{g}$ lane) were separated on SDS-polyacrylamide gel electrophoresis and transferred onto polyvinylidene difluoride membrane (Immobilion-P; Millipore, Bedford, MA USA). Membranes were then blocked with $5 \%$ nonfat milk, washed briefly, incubated with primary antibodies at $4{ }^{\circ} \mathrm{C}$ overnight, and then incubated with corresponding HRP-conjugated secondary antibodies for $1 \mathrm{~h}$ at room temperature. Protein bands were visualized by incubating membranes with chemiluminescence reagents before exposure to X-ray film.

Caspase-3 activity assay. Cells were harvested by centrifugation and washed twice with PBS. The cell pellets were lysed with $100 \mu$ l lysis buffer (BD Pharmingen, Cat. No. 559759) and the lysates were incubated with Ac-DEVD-pNA (substrate for caspase-3). After incubation for $2 \mathrm{~h}$ at $37^{\circ} \mathrm{C}$, released $p$-nitroanilide was detected at $405 \mathrm{~nm}$ using a DTX-880 microplate reader (Beckman Coulter Inc., Fullerton, CA, USA). Caspase activity was normalized to protein content and expressed as a percentage of that for control cells.

Determination of intracellular ROS. The level of intracellular ROS was assessed by measuring the oxidation of $2^{\prime}, 7^{\prime}$-dichlorodihydrofluorescin diacetate as described previously. ${ }^{46}$ Values were normalized to the protein content and expressed as percentage of those for control cells. In addition, ROS levels were also detected by using flow cytometry analysis.

Assay for nuclear condensation and ultra-structural observation. Cancer cells were cultured in with RPMI 1640 medium, and treated with fluvastatin from 0-10 $\mu \mathrm{m}$ for $24 \mathrm{~h}$. Nuclear condensation was examined with DAP staining as described previously. ${ }^{50}$ In brief, cells were then collected by centrifugation. The pooled cell pellets were fixed in $4 \%$ formaldehyde, washed with ice-cold PBS. Cells were then stained with $2.5 \mu \mathrm{g} / \mathrm{ml} \mathrm{DAPI} \mathrm{solution} \mathrm{for} 10 \mathrm{~min}$ at room temperature, washed, resuspended and a fraction of the suspension was smeared on a slide. The slide was air dried, mounted with VECTASHIELD mounting medium, and examined under a DMI 4000 fluorescence microscope (Leica, Germany).

In addition, the transmission electron microscopy was utilized for analyzing the ultra-structural images of nucleolus. In brief, treated cells were collected by centrifugation, samples were then fixed in $2.5 \%$ glutaraldehyde (Sigma-Aldrich, St Louis, MO, USA) for $24 \mathrm{~h}$, washed in $0.1 \mathrm{~m}$ phosphate buffer (pH 7.4), post-fixed in $1 \%$ osmium tetroxide (Polysciences, Warrington, PA, USA) in $0.1 \mathrm{~m}$ phosphate buffer ( $\mathrm{pH} 7.4)$ and subsequently dehydrated in increasing concentrations of alcohol. The samples were impregnated with prophylene oxide (Merck-Schuchardt Inc., Hohenbrunn, Germany) and embedded in epoxy resin embedding media. After a light microscopic examination of semi-thin sections and staining with $2 \%(\mathrm{w} / \mathrm{v})$ uranyl acetate and $1 \%(\mathrm{w} / \mathrm{v})$ lead citrate, and then observed with a JEM-1200EX II (Jeol, Japan) transmission electron microscope.

Statistical analysis. All data are presented as the mean \pm S.E.M. of at least three separate experiments. Statistical analysis was performed using one-way ANOVA followed by Dunnett's multiple comparison test. Comparisons between two groups were analyzed using the Student's $t$-test. A $P$-value of less than 0.05 was considered to be statistically significant.

\section{Conflict of Interest}

The authors declare no conflict of interest.

Acknowledgements. This work was supported by grants from National Natural Science Foundation of China $(81100079,81270183,81211140351)$ Guangdong Natural Science Foundation (S2011040003230), Fundamental Research Funds for the Central Universities (Ji Nan University) (21611301, 21612410, 21612356), Foundation for Distinguished Young Talents in Higher Education of Guangdong (34311007), Research Foundation for Recruitment Talents of Ji Nan University (50624058), China.
1. Caligaris-Cappio F, Hamblin TJ. B-cell chronic lymphocytic leukemia: a bird of a different feather. J Clin Oncol 1999; 17: 399-408.

2. Hamblin TJ, Oscier DG. Chronic lymphocytic leukaemia: the nature of the leukaemic cell. Blood Rev 1997; 11: 119-128.

3. Garcia-Munoz R, Galiacho VR, Llorente L. Immunological aspects in chronic lymphocytic leukemia (CLL) development. Ann Hematol 2012; 91: 981-996.

4. Stilgenbauer S, Zenz T. Understanding and managing ultra high-risk chronic lymphocytic leukemia. Hematology Am Soc Hematol Educ Program 20102010 481-488.

5. Hamblin TJ, Davis Z, Gardiner A, Oscier DG, Stevenson FK. Unmutated Ig V(H) genes are associated with a more aggressive form of chronic lymphocytic leukemia. Blood 1999; 94: 1848-1854.

6. Hanada M, Delia D, Aiello A, Stadtmauer E, Reed JC. bcl-2 gene hypomethylation and high-level expression in B-cell chronic lymphocytic leukemia. Blood 1993; 82: 1820-1828

7. Benekli M, Baer MR, Baumann H, Wetzler M. Signal transducer and activator of transcription proteins in leukemias. Blood 2003; 101: 2940-2954.

8. Qi XF, Kim DH, Yoon YS, Li JH, Jin D, Teng YC et al. Fluvastatin inhibits expression of the chemokine MDC/CCL22 induced by interferon-gamma in HaCaT cells, a human keratinocyte cell line. Br J Pharmacol 2009; 157: 1441-1450.

9. Kotamraju S, Williams CL, Kalyanaraman B. Statin-induced breast cancer cell death: role of inducible nitric oxide and arginase-dependent pathways. Cancer Res 2007; 67: 7386-7394.

10. Koyuturk M, Ersoz M, Altiok N. Simvastatin induces apoptosis in human breast cancer cells: $p 53$ and estrogen receptor independent pathway requiring signalling through JNK. Cancer Lett 2007; 250: 220-228.

11. Tu YS, Kang XL, Zhou JG, Lv XF, Tang YB, Guan YY. Involvement of Chk1-Cdc25A-cyclin A/CDK2 pathway in simvastatin induced S-phase cell cycle arrest and apoptosis in multiple myeloma cells. Eur J Pharmacol 2011; 670: 356-364.

12. Mohammed A, Qian L, Janakiram NB, Lightfoot S, Steele VE, Rao CV. Atorvastatin delays progression of pancreatic lesions to carcinoma by regulating PI3/AKT signaling in p48Cre/ + LSL-KrasG12D/ + mice. Int J Cancer 2012; 131: 1951-1962.

13. Pelaia G, Gallelli L, Renda T, Fratto D, Falcone D, Caraglia M et al. Effects of statins and farnesyl transferase inhibitors on ERK phosphorylation, apoptosis and cell viability in nonsmall lung cancer cells. Cell Prolif 2012; 45: 557-565.

14. Moreau AS, Jia X, Patterson CJ, Roccaro AM, Xu L, Sacco A et al. The HMG-CoA inhibitor, simvastatin, triggers in vitro anti-tumour effect and decreases IgM secretion in Waldenstrom macroglobulinaemia. Br J Haematol 2008; 142: 775-785.

15. Cemeus C, Zhao TT, Barrett GM, Lorimer IA, Dimitroulakos J. Lovastatin enhances gefitinib activity in glioblastoma cells irrespective of EGFRvill and PTEN status. J Neurooncol 2008; 90: 9-17

16. Riganti C, Doublier S, Costamagna C, Aldieri E, Pescarmona G, Ghigo D et al. Activation of nuclear factor-kappa $B$ pathway by simvastatin and RhoA silencing increases doxorubicin cytotoxicity in human colon cancer HT29 cells. Mol Pharmacol 2008; 74: 476-484.

17. Sanchez CA, Rodriguez E, Varela E, Zapata E, Paez A, Masso FA et al. Statin-induced inhibition of MCF-7 breast cancer cell proliferation is related to cell cycle arrest and apoptotic and necrotic cell death mediated by an enhanced oxidative stress. Cancer Invest 2008; 26: 698-707.

18. Sodha NR, Boodhwani M, Ramlawi B, Clements RT, Mieno S, Feng J et al. Atorvastatin increases myocardial indices of oxidative stress in a porcine model of hypercholesterolemia and chronic ischemia. J Card Surg 2008; 23: 312-320.

19. Gajski G, Garaj-Vrhovac V, Orescanin V. Cytogenetic status and oxidative DNA-damage induced by atorvastatin in human peripheral blood lymphocytes: standard and Fpgmodified comet assay. Toxicol Appl Pharmacol 2008; 231: 85-93

20. Schumacker PT. Reactive oxygen species in cancer cells: live by the sword, die by the sword. Cancer Cell 2006; 10: 175-176.

21. Waris $G$, Ahsan $H$. Reactive oxygen species: role in the development of cancer and various chronic conditions. J Carcinog 2006; 5: 14.

22. Chen $\mathrm{Y}$, McMillan-Ward E, Kong J, Israels SJ, Gibson SB. Oxidative stress induces autophagic cell death independent of apoptosis in transformed and cancer cells. Cell Death Differ 2008; 15: 171-182.

23. Simons AL, Ahmad IM, Mattson DM, Dornfeld KJ, Spitz DR. 2-Deoxy-D-glucose combined with cisplatin enhances cytotoxicity via metabolic oxidative stress in human head and neck cancer cells. Cancer Res 2007: 67: 3364-3370.

24. Nogueira V, Park Y, Chen CC, Xu PZ, Chen ML, Tonic I et al. Akt determines replicative senescence and oxidative or oncogenic premature senescence and sensitizes cells to oxidative apoptosis. Cancer Cell 2008; 14: 458-470.

25. Hay N. The Akt-mTOR tango and its relevance to cancer. Cancer Cell 2005; 8: 179-183.

26. Yamazaki H, Suzuki M, Aoki T, Morikawa S, Maejima T, Sato $\mathrm{F}$ et al. Influence of 3-hydroxy-3-methylglutaryl coenzyme A reductase inhibitors on ubiquinone levels in rat skeletal muscle and heart: relationship to cytotoxicity and inhibitory activity for cholesterol synthesis in human skeletal muscle cells. J Atheroscler Thromb 2006; 13: 295-307.

27. Orrenius S. Mitochondrial regulation of apoptotic cell death. Toxicol Lett 2004; 149: 19-23.

28. Deveraux QL, Roy N, Stennicke HR, Van Arsdale T, Zhou Q, Srinivasula SM et al. IAPS block apoptotic events induced by caspase-8 and cytochrome $\mathrm{c}$ by direct inhibition of distinct caspases. EMBO J 1998; 17: 2215-2223. 
29. Slee EA, Harte MT, Kluck RM, Wolf BB, Casiano CA, Newmeyer DD et al. Ordering the cytochrome $c$-initiated caspase cascade: hierarchical activation of caspases-2, -3, -6, -7, -8, and -10 in a caspase-9-dependent manner. J Cell Biol 1999; 144: 281-292.

30. Nicholson DW, Ali A, Thornberry NA, Vaillancourt JP, Ding CK, Gallant M et al. Identification and inhibition of the ICE/CED-3 protease necessary for mammalian apoptosis. Nature 1995; 376: 37-43.

31. Oliver FJ, de la Rubia G, Rolli V, Ruiz-Ruiz MC, de Murcia G, Murcia JM. Importance of poly(ADP-ribose) polymerase and its cleavage in apoptosis. Lesson from an uncleavable mutant. J Biol Chem 1998; 273: 33533-33539.

32. Capitani N, Baldari CT. The Bcl-2 family as a rational target for the treatment of B-cell chronic lymphocytic leukaemia. Curr Med Chem 2010; 17: 801-811.

33. Nilsson EM, Brokken LJ, Harkonen PL. Fibroblast growth factor 8 increases breast cancer cell growth by promoting cell cycle progression and by protecting against cell death. Exp Cell Res 2010; 316: 800-812.

34. Sebolt-Leopold JS, Dudley DT, Herrera R, Van Becelaere K, Wiland A, Gowan RC et al. Blockade of the MAP kinase pathway suppresses growth of colon tumors in vivo. Nat Med 1999; 5: 810-816.

35. Cheng M, Sexl V, Sherr CJ, Roussel MF. Assembly of cyclin D-dependent kinase and titration of p27Kip1 regulated by mitogen-activated protein kinase kinase (MEK1). Proc Natl Acad Sci USA 1998; 95: 1091-1096.

36. Xiao $\mathrm{H}$, Yang CS. Combination regimen with statins and NSAIDs: a promising strategy for cancer chemoprevention. Int J Cancer 2008; 123: 983-990.

37. Chen $\mathrm{CH}$, Chen SJ, Su CC, Yen CC, Tseng TJ, Jinn TR et al. Chloroacetic acid induced neuronal cells death through oxidative stress-mediated p38-MAPK activation pathway regulated mitochondria-dependent apoptotic signals. Toxicology 2012.

38. Liu Y, Ge J, Li Q, Gu L, Guo X, Ma ZG et al. Anisomycin induces apoptosis of glucocorticoid resistant acute lymphoblastic leukemia CEM-C1 cells via activation of mitogen-activated protein kinases p38 and JNK. Neoplasma 2013; 60: 101-110.

39. Lewis TS, Shapiro PS, Ahn NG. Signal transduction through MAP kinase cascades. Adv Cancer Res 1998; 74: 49-139.

40. Hoshino R, Chatani Y, Yamori T, Tsuruo T, Oka H, Yoshida O et al. Constitutive activation of the $41-/ 43-k D a$ mitogen-activated protein kinase signaling pathway in human tumors. Oncogene 1999; 18: 813-822.
41. Celec $P$, Behuliak M. The lack of non-steroid isoprenoids causes oxidative stress in patients with mevalonic aciduria. Med Hypotheses 2008; 70: 938-940.

42. Sirvent $P$, Mercier J, Lacampagne A. New insights into mechanisms of statin-associated myotoxicity. Curr Opin Pharmacol 2008; 8: 333-338.

43. Trachootham D, Zhou Y, Zhang H, Demizu Y, Chen Z, Pelicano $\mathrm{H}$ et al. Selective killing of oncogenically transformed cells through a ROS-mediated mechanism by beta-phenylethyl isothiocyanate. Cancer Cell 2006; 10: 241-252.

44. Laezza C, Fiorentino L, Pisanti S, Gazzerro P, Caraglia M, Portella G et al. Lovastatin induces apoptosis of k-ras-transformed thyroid cells via inhibition of ras farnesylation and by modulating redox state. J Mol Med (Berl) 2008; 86: 1341-1351.

45. Alegret M, Silvestre JS. Pleiotropic effects of statins and related pharmacological experimental approaches. Methods Find Exp Clin Pharmacol 2006; 28: 627-656.

46. Qi XF, Kim DH, Yoon YS, Kim SK, Cai DQ, Teng YC et al. Involvement of oxidative stress in simvastatin-induced apoptosis of murine CT26 colon carcinoma cells. Toxicol Lett 2010; 199: 277-287.

47. Forsmark-Andree P, Dallner G, Ernster L. Endogenous ubiquinol prevents protein modification accompanying lipid peroxidation in beef heart submitochondrial particles. Free Radic Biol Med 1995; 19: 749-757.

48. Bizzarri R, Cerbai B, Signori F, Solaro R, Bergamini E, Tamburini I et al. New perspectives for (S)-dolichol and (S)- nor dolichol synthesis and biological functions. Biogerontology 2003; 4: 353-363.

49. Bergamini E, Bizzarri R, Cavallini G, Cerbai B, Chiellini E, Donati A et al. Ageing and oxidative stress: a role for dolichol in the antioxidant machinery of cell membranes? J Alzheimers Dis 2004; 6: 129-135.

50. Hsiao WT, Tsai MD, Jow GM, Tien LT, Lee YJ. Involvement of Smac, p53, and caspase pathways in induction of apoptosis by gossypol in human retinoblastoma cells. Mol Vis 2012; 18: 2033-2042.

cc) (i) (3) $\odot$ Cell Death and Disease is an open-access journal published by Nature Publishing Group. This work is licensed under the Creative Commons Attribution-NonCommercial-No Derivative Works 3.0 Unported License. To view a copy of this license, visit http://creativecommons.org/licenses/by-nc-nd/3.0/ 